\title{
Subcooling Cryogenic Propellants for Long Duration Space Exploration
}

\author{
Shuvo Mustafi ${ }^{1}$, Edgar Canavan ${ }^{2}$ \\ NASA Goddard Space Flight Center, Greenbelt, Maryland, 20771, USA \\ Wesley Johnson ${ }^{3}$ \\ NASA Kennedy Space Center, Kennedy Space Center, Florida, 32899, USA \\ Bernard Kutter ${ }^{4}$ \\ United Launch Alliance, Denver, Colorado, 80127, USA \\ and \\ Jeff Shull ${ }^{5}$ \\ Barber Nichols, Arvada, Colorado, 80002, USA
}

\begin{abstract}
The use of cryogenic propellants such as hydrogen and oxygen is crucial for exploration of the solar system because of their superior specific impulse capability. Future missions may require vehicles with the flexibility to remain in orbit or travel in space for months, necessitating long-term storage of these cryogens. One powerful technique for easing the challenge of cryogenic fluid storage is to remove energy from the cryogenic propellant by isobaricly subcooling them below their normal boiling point prior to launch. The isobaric subcooling of the cryogenic propellant will be performed by using a cold pressurant to maintain the tank pressure while the cryogen's temperature is simultaneously reduced. After launch, even with the use of the best insulation systems, heat will leak into the cold cryogenic propellant tank. However, the large heat capacity available in highly subcooled cryogenic propellants allows them to absorb the energy that leaks into the tank until the cryogen reaches its operational thermodynamic condition. During this period of heating of the subcooled cryogen there will be no loss of the propellant due to venting for pressure control. This simple technique can extend the operational life of a spacecraft or an orbital cryogenic depot many months with minimal mass penalty. Subcooling technologies for cryogenic propellants would thus provide the Exploration Systems Mission Directorate with an enhanced level of mission flexibility. However, there are a few challenges associated with subcooling cryogenic propellants since compact subcooling ground support equipment has not been demonstrated. This paper explores the beneficial impact of subcooling cryogenic propellants on the launch pad for long-term cryogenic propellant storage in space and proposes a novel method for implementing subcooling of cryogenic propellants for spacecraft such as the Ares V Earth Departure Stage (EDS). Analysis indicates that with a careful strategy to handle the subcooled cryogen it would be possible to store cryogenic propellants in space for many months without venting. A concept for subcooling the cryogenic propellant relatively quickly and inexpensively on the launch pad - the thermodynamic cryogen subcooler (TCS) - will be presented. Important components of the TCS and an associated subcooled cryogen tank (SCT) will be discussed in this paper. Results from a preliminary thermodynamic model of the performance of a TCS for an EDS sized hydrogen tank will also be presented.
\end{abstract}

\section{Introduction}

Liquid hydrogen and liquid oxygen has the highest specific impulse of any practical chemical propellant combination, providing the greatest payload mass capability. Future missions may require vehicles with the flexibility to remain in orbit or travel in space for months, necessitating long-term storage of these cryogens. The

\footnotetext{
${ }^{1}$ Aerospace Engineer, Cryogenics and Fluids Branch, NASA-GSFC/ 552, Greenbelt, MD 20771, AIAA Member

${ }^{2}$ Aerospace Engineer, Cryogenics and Fluids Branch, NASA - GSFC/ 552, Greenbelt, MD 20771

${ }^{3}$ Cryogenic Engineer, Applied Technology Division, M/S KT-E, Kennedy Space Center, FL 32899, AIAA Member

${ }^{4}$ Sr. Staff, Manager Advanced Programs, United Launch Alliance, Denver, CO 80127, AIAA Senior Member

${ }^{5}$ Sales Engineer, Barber Nichols, Arvada, CO 80002
} 
inherent low temperature of cryogens results in cryogen tanks even with the best insulation systems becoming heat sinks. The desired thermodynamic condition in the tank is primarily governed by the allowable pressure and temperature of the cryogenic propellant for engine operation and by the need to prevent tank over-pressurization. As heat leaks into the cryogen tank, the cryogen has to be vented into space in order to maintain the tank contents within the prescribed thermodynamic conditions for engine operation. The benefits of the high specific impulse of cryogenic propellants could potentially be negated if a large fraction of the cryogen has to be vented during the required long duration storage since the mass of the cryogenic propellant system must take into account this vented cryogen. The isobaric subcooling of cryogenic propellants below their boiling point at atmospheric pressure prior to launch could allow long duration storage of these cryogenic propellants before venting has to be initiated.

Previous efforts at studying subcooling have focused primarily on "densifying" the cryogenic propellants with a principal objective of either reducing the needed tank volume and the gross lift-off weight or to increase the launch capacity by filling a given tank with more propellant. ${ }^{1,2}$ The techniques proposed have involved the use of large refrigeration plants employing a variety of refrigeration cycles. A difficulty with this approach has been the large resource requirements needed when using a large footprint refrigeration plant - cooling powers upto megawatts are needed. ${ }^{3}$ This size and weight of the refrigeration plant poses a serious challenge to integration into a launch complex. A Thermodynamic Cryogen Subcooler (TCS) and an associated Subcooled Cryogen Tank (SCT) are proposed in this paper to potentially reduce the resource requirements and footprint necessary for subcooling the cryogenic propellants allowing for easier integration into launch facilities. The TCS is ground support equipment (GSE) that is entirely external to the cryogen tank that is being subcooled. A similar densifying scheme using a thermodynamic vent system (TVS) has been proposed in the past but not explicitly studied. ${ }^{2}$ In the 1990s NASA Glenn Research Center (GRC) - formerly NASA/ Lewis Research Center - demonstrated densification using TVS principles for the X-33 program. ${ }^{1}$ A major distinction between the TCS and GRC techniques is that for the TCS both the cryogen that is being chilled and the cryogen that is performing the chilling share the same source - the tank of cryogen that is being subcooled - this should simplify launch pad integration.

\section{Removing Energy from Cryogenic Propellants by Isobaric Subcooling}

\section{A. Subcooling Thermodynamics}

This paper describes an alternate method for removing energy or de-energizing the cryogenic propellant using isobaric subcooling. Figure 1 helps to explain the process of isobaric subcooling proposed in this paper and contrast it with densification and isothermal subcooling. ${ }^{4}$

The thermodynamic condition " $N$ " is the normal boiling point of hydrogen. This is the condition that most launch tanks are loaded at. If the thermodynamic state (its pressure and temperature) of the cryogen is being reduced while following the liquid-vapor saturation curve - arrow " $N D$ " - this process is termed as "densification." The densified propellant can then be fit in smaller tanks as has been proposed for the X-33 program. Alternately more propellant can be fit into existing tanks, as had been proposed for the Space Shuttle program. This is one potential way to de-energize the cryogenic propellant. Densification has been demonstrated by various means including heat exchanging with a bath of subatmospheric hydrogen ${ }^{1}$ and direct cooling using a cryocooler ${ }^{5}$. If the cryogen is pressurized keeping the temperature constant - arrow " $N T$ " - an isothermal subcooling process is accomplished. This is the process that is regularly performed on the launch pad to ensure that the tank is subcooled so that there is no cavitation during engine operation. If the cryogen's temperature is reduced while keeping the total pressure in the tank constant- arrow " $N B$ " - an isobaric subcooling process is accomplished. This process allows a substantial deenergization of the cryogenic propellant with potentially small resource requirements. As the cryogen is subcooled and its thermodynamic state - the temperature and the pressure - drops, the cryogenic propellant densifies. This increase in density and resulting decrease in volume can be exploited to make smaller tanks or fit more propellant into the same tank, as has been proposed in previous "densification" studies. However in this application of isobaric subcooling for long-term cryogen storage in space the tank volumes are kept at the nominal size so that while the cryogen absorbs energy in space it can re-expand. Another consequence of the reduction in the thermodynamic state during subcooling is that while on the launch pad the tank would be under atmospheric compression unless a noncondensable pressurant is added to the system. For hydrogen, cold helium is added as pressurant to the tank which, if required, can later be preferentially vented to the vacuum of space or transferred to another tank while the stage is accelerating towards a loiter orbit or through settling maneuvers while it is in the loiter orbit. 


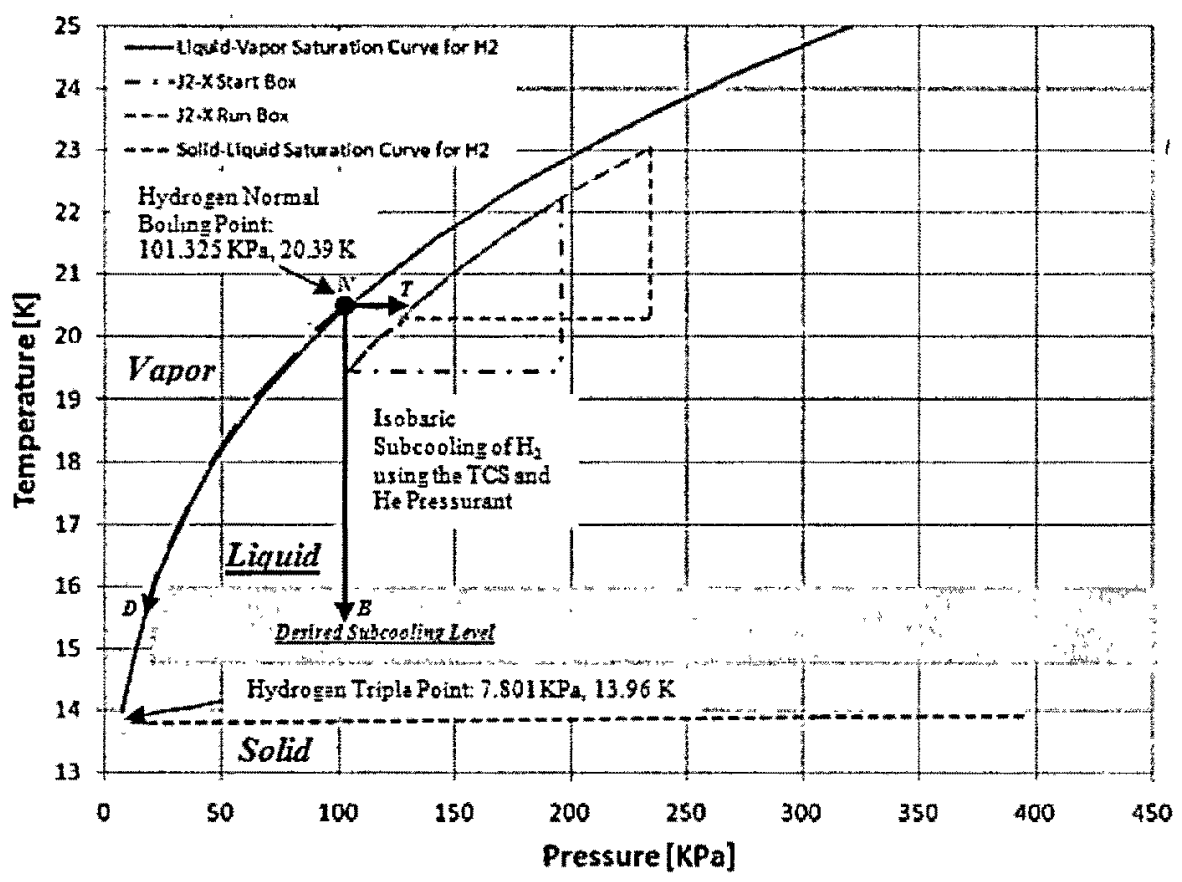

Figure 1. Thermodynamics of the TCS process and the $\mathrm{J} 2$-X engine operating conditions.

Figure 1 also shows the thermodynamics of the TCS process and the J2-X Engine operating conditions. The J2$\mathrm{X}$ engines are being planned for use with the Ares V Earth Departure Stage (EDS). As in the case of the Space Shuttle, Atlas V and Delta IV operations, hydrogen is loaded into the tank at the launch pad at its normal boiling point - its saturation point at sea level, " $N$ " $(20.39 \mathrm{~K}$ and $1 \mathrm{~atm}$. $=101.325 \mathrm{KPa})$. This hydrogen can then be isobarically subcooled (following the Arrow "NB" on Figure 1) to around $15 \mathrm{~K}$ on the launch pad using the TCS or some other refrigeration method ${ }^{3}$ while maintaining the pressure in the tank at $1 \mathrm{~atm}$. using cold helium to avoid crushing the hydrogen tank. The partial pressure of the hydrogen in the tank will be $0.13 \mathrm{~atm}$. at $15 \mathrm{~K}$. The solubility of helium in hydrogen is less than $0.1 \%$ by mole at these pressures and temperatures. ${ }^{6}$ The desired level of subcooling is between $14.5 \mathrm{~K}$ and $16 \mathrm{~K}$ to allow sufficient buffer between the storage conditions and the slush hydrogen conditions defined by the solid-liquid saturation curve. The J2-X engines operating conditions are between $19.3 \mathrm{~K}$ at $103.8 \mathrm{KPa}$ (the start box low end condition) and $23.1 \mathrm{~K}$ at $234.6 \mathrm{KPa}$. The start box high end condition for the $\mathrm{J} 2-\mathrm{X}$ is $22.2 \mathrm{~K}$ at $196 \mathrm{KPa}$. For subcooling to be used for long-term storage of hydrogen on the EDS, the J2-X engine would have to be qualified for operation under these subcooled conditions. Alternatively a heater could be used to bring the thermodynamic conditions of the stored subcooled cryogen up to its operational conditions. Although the $\mathrm{J} 2-\mathrm{X}$ engine has not been operated with the highly subcooled fluid that is being proposed in this paper RL-10 engines have been operated under these subcooled conditions. ${ }^{7}$ The Altair descent engines are planned to be RL-10 derived and hence the Altair program might want to consider subcooling their propellant.

\section{B.' Subcooling Benefits}

Figure 2 shows a notional wet mass comparison of a subcooled EDS Hydrogen tank to a standard EDS Hydrogen tank, both with about 40 layers of high performance multi-layer insulation (MLI) providing thermal protection. The total heat load with this level of thermal protection on both EDS tanks in a notional $300 \mathrm{~K}$ vacuum environment in space is approximately $69 \mathrm{~W}$. This graph depicts the resulting variation of required wet mass with mission duration in order to maintain a constant operational $\Delta \mathrm{V}$ capability for both the subcooled tank and the standard tank. Both types of tanks are loaded on the launch pad at sea level conditions. The hydrogen in the standard tank is assumed to be at $\sim 20.4 \mathrm{~K}$ and the hydrogen in the subcooled tank is initially assumed to be at $\sim 15 \mathrm{~K}$ after being subcooled on the launch pad. Since the J2-X start condition can be as high as $22,2 \mathrm{~K}$ at $196 \mathrm{KPa}$ both types of tanks will absorb heat in space until they reach the start box high end condition. Once the stored hydrogen reaches this condition by absorbing heat in space, pressure control and venting of the cryogen would be required in order to 


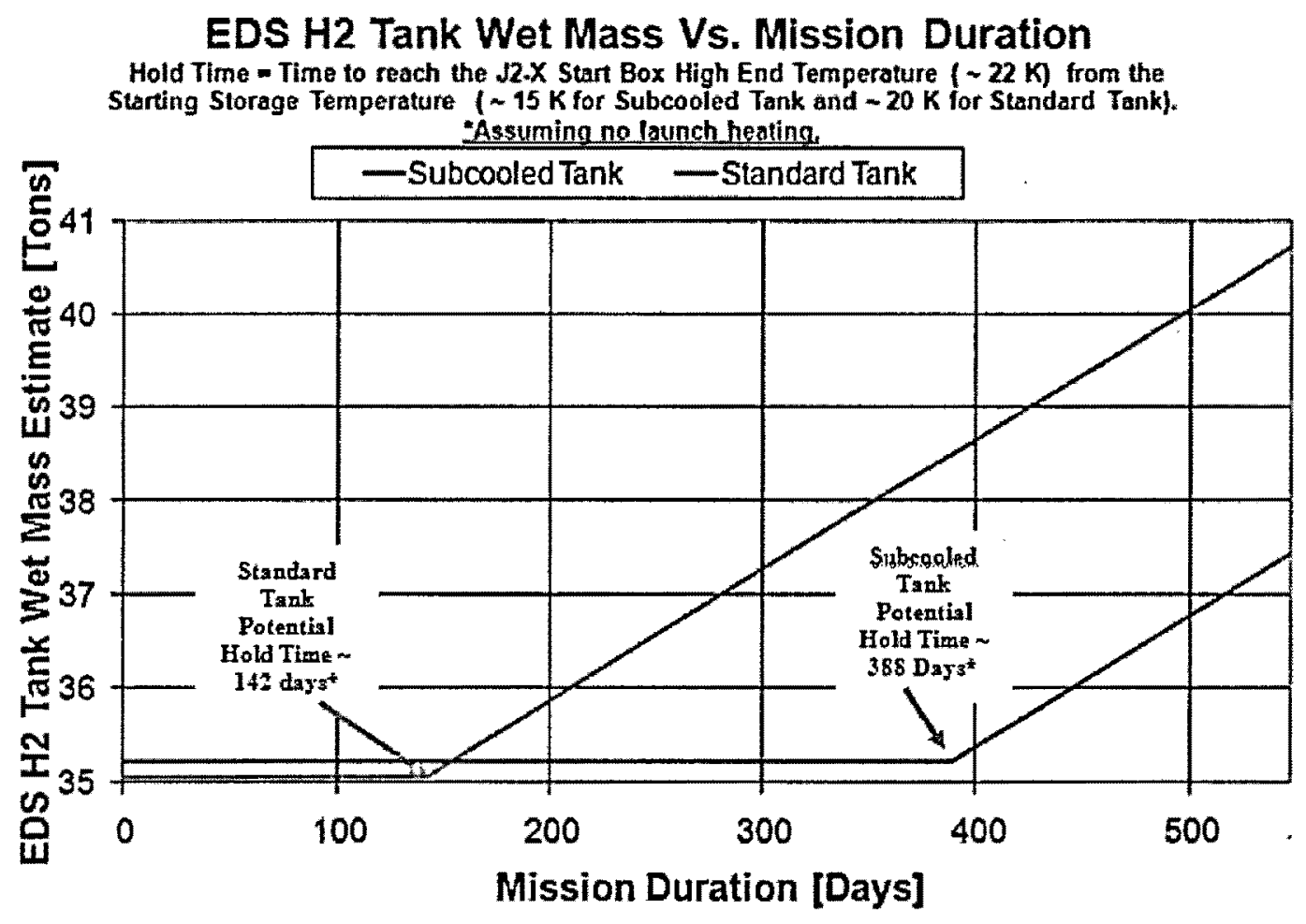

Figure 2. A notional wet mass comparison of a subcooled tank to a standard tank.

ensure that the stored hydrogen can still be used to start the engine within its operational parameters. The time required by the hydrogen to reach the high end start box thermodynamic condition is defined as the hold time for the tank. Assuming that both the tanks have about 40 layers of high performance MLI and that there is no launch thermal loads the hold time for the sucooled tank would be 388 days compared to the hold time of only 142 days for a standard tank.

It is important to recognize that the analysis in Figure 2 is a first order approximation of the comparative hold time. If for example the launch thermal loads can be accurately estimated and added to this analysis the hold time would reduce for both types of tanks. However, Figure 2 is illustrative in demonstrating the relative margin of hundreds of days that subcooling may provide. Subcooling will allow the inevitable imperfections in the thermal management of these cryogenic systems such as launch thermal load uncertainty and MLI performance uncertainty to be better tolerated.

Subcooling can help overcome Constellation's current predicted Loss of Mission estimates due to launch delay. The extended hold times enabled with subcooling would significantly benefit launch logistics of the Exploration architecture. If the Ares $\mathrm{V}$ is launched first, launch delays for the Ares I ranging into weeks and months will become acceptable with a substantial reduction to the risk of mission loss. Subcooling propellants will make the design and operation of spacecraft such as the EDS and Altair, as well as cryogenic orbital depots far simpler. This may also prove to be useful for a cryogenic hydrogen and oxygen Orion propellant module option.

There are other significant potential benefits to subcooling cryogenic propellants. Subcooling cryogenic propellants may enable higher $\Delta V$ outer planetary and asteroid missions while increasing their instrument and payload capability. Proposed cryogenic depots and hydrogen radiation shield technologies for long duration Martian missions would benefit from subcooling cryogenic própellants. This technology may also enhance advanced high specific impulse propulsion technologies such as electric, magnetic, or nuclear-thermal systems. 


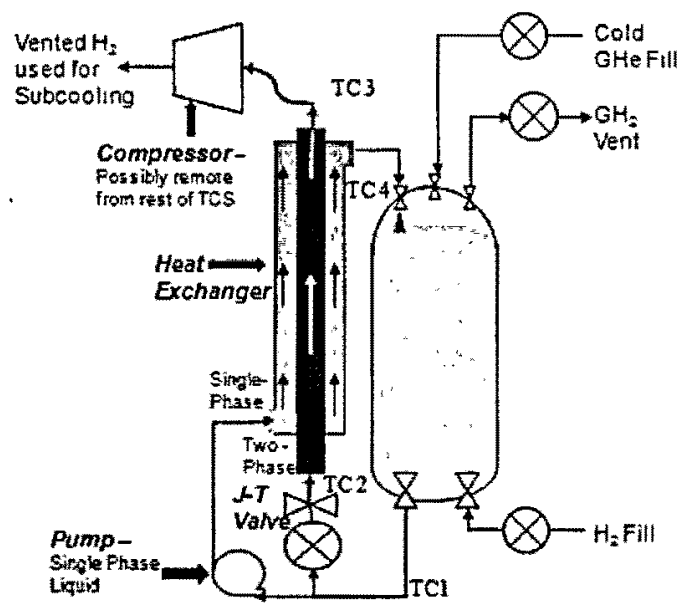

Figure 3. The TCS concept for isobaric subcooling cryogens on the launch pad.

\section{Thermodynamic Cryogen Subcooler}

Figure 3 shows a notional configuration for the TCS that is being proposed for a launch pad subcooling system. The cryogenic propellant that is being subcooled, for example hydrogen, will be extracted from the tank. Some of this hydrogen that is extracted will be passed through a Joule-Thomson (J-T) valve that expands the hydrogen isenthalpicly. The hydrogen on the upstream side of the J-T valve, at thermodynamic condition 1(TC 1), will be at the temperature of the hydrogen in the tank (initially $20 \mathrm{~K}$ ). The hydrogen on the downstream side of the $\mathrm{J}$-T valve (TC 2) will have the same enthalpy as the hydrogen on the upstream side, but at a lower pressure $(\sim 0.1$ atm.) and substantially lower temperature $(\sim 15 \mathrm{~K})$. While going through this expansion the hydrogen at TC 2 becomes a two-phase fluid. Most of the liquid hydrogen extracted from the tank at TC 1 will be pumped into the outside tube of a concentric tube heat exchanger - the single-phase tube. The two-phase hydrogen at TC 2 is passed into the center tube of the concentric tube heat exchanger - the two-phase tube. Since the hydrogen in the twophase tube is at a lower temperature than the hydrogen in the single-phase tube it can extract heat from the hydrogen in the single-phase tube and thus subcool the propellant. The two-phase hydrogen will increase its quality along the two-phase tube until it totally vaporizes and is vented (TC 3) to a flare stack through a compressor. This compressor will probably be the heaviest and most power intensive portion of the TCS and hence it might be remote from the rest of the TCS. The subcooled hydrogen at the end of the single-phase tube (TC 4) is then fed back into the hydrogen tank. As the bulk hydrogen in the tank subcools by this process, its density increases so the tank has to be backfilled with cold helium in order to prevent the tank from experiencing a compressive atmospheric load. An alternate approach might be to have the single-phase fluid flowing in the center tube of the heat exchanger, with the two-phase fluid flowing on the outside tube of the heat exchanger. This scheme would allow the two-phase fluid that is performing the subcooling to protect the single-phase fluid that is being subcooled from parasitic heat inputs. However this alternate scheme is more difficult to model and scale. In either scheme the heat exchanger will be thermally isolated from parasitic heat inputs by using a vacuum outer jacket and MLI.

By using the cooling enthalpy available in the vented hydrogen the need for a high-capacity refrigeration system is diminished. Models indicate that the required subcooling for an EDS sized tank can be achieved with kilo-watts of electrical power at the launch pad instead of the mega-watts of electrical power required by large refrigeration plants servicing similar sized tanks. ${ }^{3,5}$ This process may also be used to subcool the other cryogenic propellants being considered by the Constellation program - methane and oxygen. It is also important to note that if the cryogen is subcooled to some degree prior to its delivery at the launch pad by systems similar to the Kennedy Space Center Integrated Refrigeration and Storage (IRAS) system, the TSC can help to subcool the cryogen further and offset the heat load on the cryogen during transit and while the cryogen is sitting in the tank on the launch pad. An IRAS type system could reduce the time required for the subcooling process. ${ }^{8}$

The important components of the TCS are the heat exchanger, the pump, the compressor and the Joule-Thomson valve. With appropriate funding the technology readiness levels (TRL) of these individual components and the TCS system can be brought to flight levels between 2014 and 2016 before the first Altair and Ares V spacecraft will fly. Although this technology may not be ready for the first Orion vehicles, it is envisioned that this technology can provide an appropriate subcooling option for any future cryogenic hydrogen and oxygen Orion vehicles.

5

American Institute of Aeronautics and Astronautics 


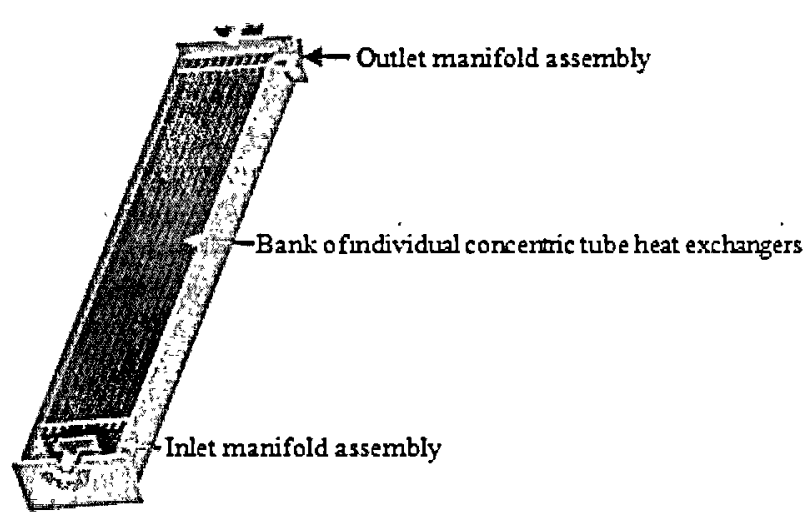

Figure 4. A notional TCS heat exchanger with a bank of concentric tube heat exchangers.

Credit: Matthew C. Kuhn - NASA/GSFC Summer 2009 Intern

The following sub-sections discuss the important components and the predicted system performance of the TCS.

\section{A. Heat Exchanger}

A major component of the TCS is the heat exchanger which will transfer heat from the higher temperature recirculated single-phase liquid cryogen that is subcooled to the vented lower temperature two-phase cryogen that is performing the cooling. The performance of the heat exchanger will determine the mass and size parameters of the TCS, which are important for the appropriate packaging of this system on the launch pad. An actual TCS would probably consist of a bank of concentric tube heat exchangers that would allow the TCS to be packaged compactly. Figure 4 depicts a notional TCS heat exchanger with a bank of individual concentric tube heat exchangers with a manifold splitting the flows near the inlet and another manifold rejoining the flows near the outlet. The researchers at NASA/GSFC have submitted a proposal for internal research and development (IRAD) during 2010 to perform the first-step of the TCS heat exchanger development: measuring the high Reynolds number two-phase flow parameters that are important for the design of simple and scalable concentric tube co-flow heat exchangers. For an EDS sized tank about 34 tons of hydrogen will have to be subcooled within a 12 hour period, leading to the necessity for high Reynolds number flows $\left(10^{5}-10^{6}\right)$ through the heat exchanger to achieve a reasonably compact design. In the future these concentric heat exchangers may provide a baseline for more advanced compact heat exchangers that are difficult to model and scale. The GSFC IRAD should advance the heat exchanger TRL to 3 and in subsequent years this TRL can be rapidly advanced to 6 .

\section{B. Pumps}

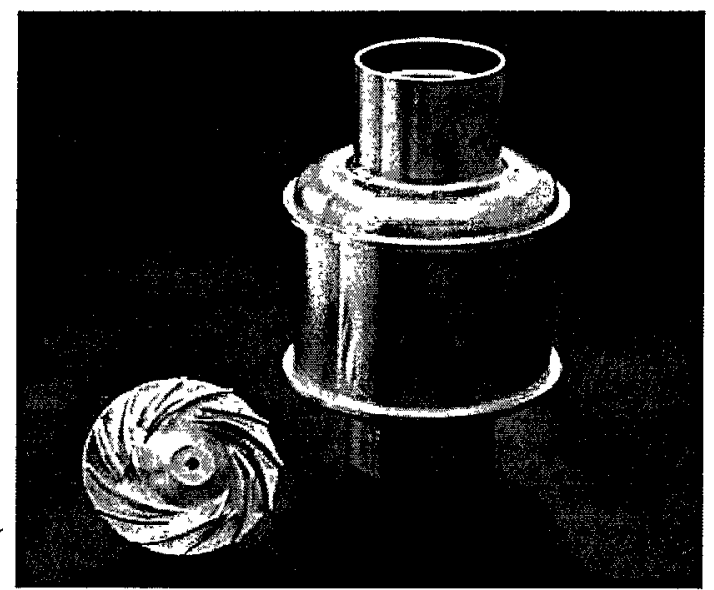

(a) An Inline $\mathrm{LH}_{2}$ Pump

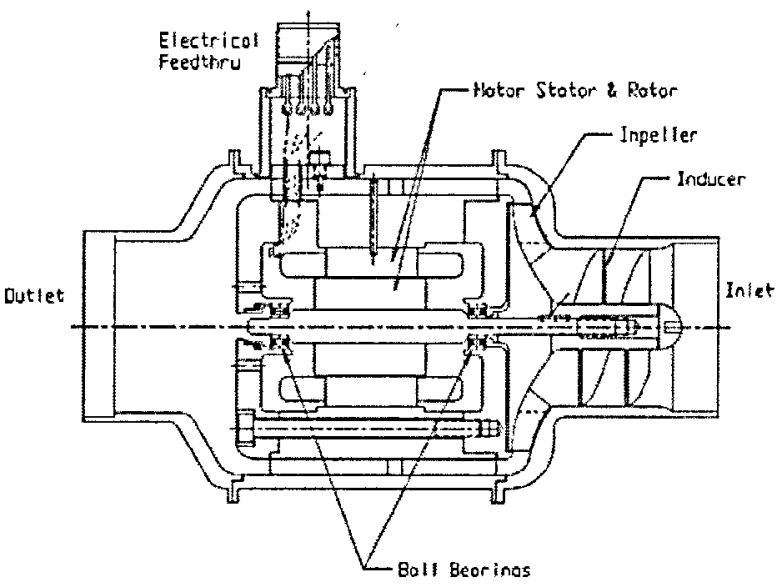

(b) Sectional View of Inline $\mathrm{LH}_{2}$ Pump

Figure 5. A subscale version of the inline liquid hydrogen pump. Credit: Barber-Nichols 
A liquid pump will be required by the TCS to facilitate liquid flow through the single tube heat exchanger for subcooling before re-injection into the tank. The liquid flow rate is quite large with a relatively small head rise so the pump is a mixed/axial flow device that is a larger version of the pump shown in Figures 5. This pump can be installed directly in the liquid hydrogen lines with insulation installed around it. The pump shaft has the motor rotor and pump impeller/inducer directly attached and riding on special ball bearings. These bearings utilize a teflon/molydisulfide cage that lubricates the ball bearing and races in the poor lubricity liquid hydrogen. The bearings have stainless steel races and ceramic balls. These bearings have been used extensively in liquid hydrogen, liquid helium and liquid nitrogen applications. The ball bearings and the motor are both kept cool by the liquid hydrogen. The liquid hydrogen flows in and out of the pump in the same axis allowing for ease of installation. The pump is controlled by a variable frequency drive (VFD) that provides a wide range of possible performances through changes in speed. This technology is well advanced with a TRL near 6.

\section{Compressor}

The hydrogen expanded across the J-T valve must be compressed prior to venting to the atmosphere after passing through the two-phase tubes of the heat exchanger. The hydrogen that is initially two-phase directly after passing through the $\mathrm{J}-\mathrm{T}$ valve will be completely vaporized by the time it passes through the heat exchanger. The compression system must take the gas at very low pressure (approximately $9.8 \mathrm{KPa}$ ) and discharge above atmospheric pressure (near $105 \mathrm{KPa}$ ). This very large pressure ratio will require approximately 4 stages of compression and large volumetric flow rates at the first stage inlet. In the late 1990's a prototype 4 stage compression system for propellant densification was tested at NASA-GRC for the aforementioned X-33 program densification demonstration. Each stage resembled the compressor shown in Figure 6. The lower portion of each of the compressors was installed in an insulated vessel while the water-cooled motors were open to the atmosphere. VFDs controlled each stage at elevated speeds to optimize performance. The TRL of this system would be at 4 and can be advanced quite quickly to 6 with sufficient system testing.

\section{Joule-Thomson Valves}

J-T valves have been extensively tested on the ground in conjunction with TVS and industrial refrigeration systems. They have been flight qualified for the Shuttle and the Centaur but never flown. It is of course not necessary for the J-T valves to have flown for this TCS application. The J-T valves are at TRL 5-6.

The J-T valves have been observed to become clogged when liquid hydrogen at a temperature range from $20.5 \mathrm{~K}$ to $24.4 \mathrm{~K}$ is flowed through them. It has been proposed that the clogging is caused by trace amounts of metastable supercooled liquid neon present in the regular hydrogen supply. However, densified liquid hydrogen at $18.2 \mathrm{~K}$, has been flown through J-T devices without any clogging for short durations. Longer duration tests with subcooled liquid hydrogen would provide useful validation of this component. ${ }^{9}$

\section{E. TCS Predicted System Performance}

The performance of the TCS is governed by many factors including the flow geometry of the heat exchanger tubes, the single-phase and two-phase flow rates, the pump efficiency, etc. One potential non-optimized subcooling scheme is presented here. The goal of the TCS is to cool the tank of cryogen from $20 \mathrm{~K}$ to about $14.5 \mathrm{~K}-16 \mathrm{~K}$ within

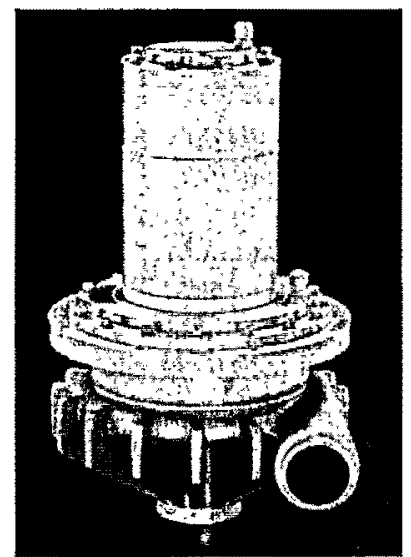

Figure 6. A cryogenic hydrogen compressor. Credit: Barber-Nichols 


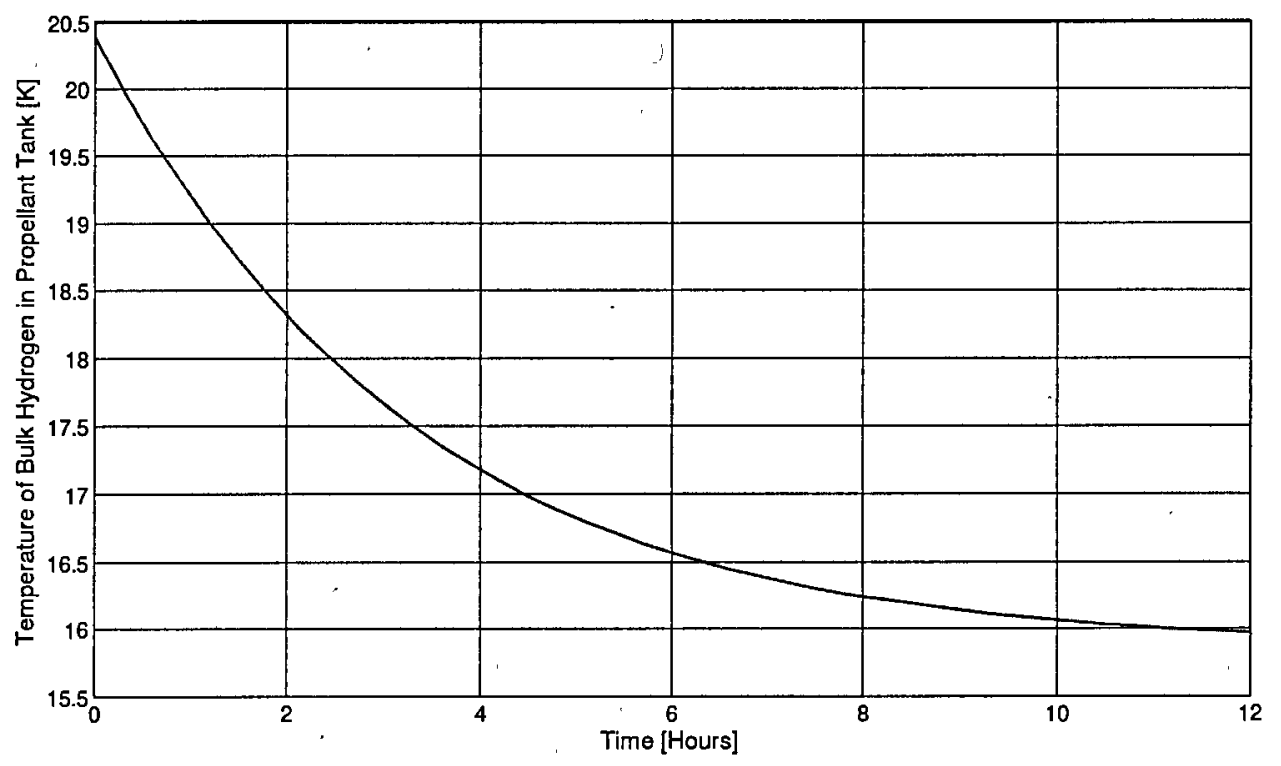

Figure 7. The cooling time history for an EDS sized tank of hydrogen using a TCS with a bank of 200 concentric tube heat exchangers.

12 hours. In order to get an idea about the performance of the TCS a transient thermodynamic model of the TCS, cryogen tank and the bulk subcooled cryogen was created using a constant single-phase mass flow-rate scheme. The analysis was performed using Engineering Equation Solver and MATLAB. The required heat transfer coefficients and pressure drop estimates were extrapolated from data in lower Reynolds number regimes since there is no data currently available at the high Reynolds number regimes needed for this application. Figure 7 shows the resulting cooling time history for an EDS sized tank for a non-optimized liquid hydrogen flow rate of $3.29 \mathrm{Kg} / \mathrm{s}$ through the single-phase tubes. This cooled single-phase liquid hydrogen is re-injected into the propellant tank after passing through the heat exchanger. The corresponding maximum flow rate in the two-phase tubes is $0.34 \mathrm{Kg} / \mathrm{s}$ of two-phase hydrogen. The required two-phase flow rate will diminish over time as the bulk fluid in the tank subcools. With this level of flow, the tank reaches a temperature of $15.97 \mathrm{~K}$ in 12 hours. Larger flow rates would result in faster cooling and lower bulk hydrogen temperatures. However this would imply that a more powerful compressor would be necessary. A system level optimization would thus be a useful exercise for the future.

The modeled heat exchanger consists of a bank of 200 concentric tube heat exchangers similar to the one shown in Figure 4. Each concentric tube heat exchanger unit had an outer diameter of $2.25 \mathrm{~cm}$ and is $3.8 \mathrm{~m}$ long. These tubes could fit in an envelope that is about $0.5 \mathrm{~m} \mathrm{x} 1 \mathrm{~m} \mathrm{x} 4 \mathrm{~m}$ and the collection of tubes would have a total mass of about $52 \mathrm{Kg}$. Each of the four compressor stages would be about $180 \mathrm{Kg}$ and consume a maximum of about $25 \mathrm{KW}$. This power consumption should drop with time as the required two-phase flow rate drops. If required these compressors can be staged separately to allow for better launch pad packaging. The compressors are similar to the ones shown in Figure 6 and are about $0.7 \mathrm{~m}$ long. The pump will use about 1-2 $\mathrm{KW}$ of power, which is accounted for in the heat exchanger cooling requirements. The heat exchanger, compressors, pumps and fluid lines will also need vacuum insulated containment structures that will add to the total TCS mass.

If the two-phase hydrogen that is converted to single-phase vapor in the bank of concentric heat exchanger tubes is not recovered, about 5.2 tons of hydrogen will be vented during this 12 hour subcooling process for an Earth Departure Stage (EDS) sized tank. Over 241 tons of liquid hydrogen is required to just fill the Ares $V$ hydrogen tanks, not including the hydrogen that is boiled-off during the fill process. So this hydrogen used for subcooling the EDS is a fraction of the total hydrogen consumption for the Constellation program, amounting to less than $\$ 26 \mathrm{~K}$ in delivered hydrogen cost per launch. ${ }^{10}$ About $220 \mathrm{Kg}$ - less than $\$ 19 \mathrm{~K}$ - of cold Helium pressurant gas will also be needed for the isobaric subcooling process per launch. The cost of the subcooling GSE - the pump, compressors, heat exchanger, and cryogenic lines - is amortized over many launches. 


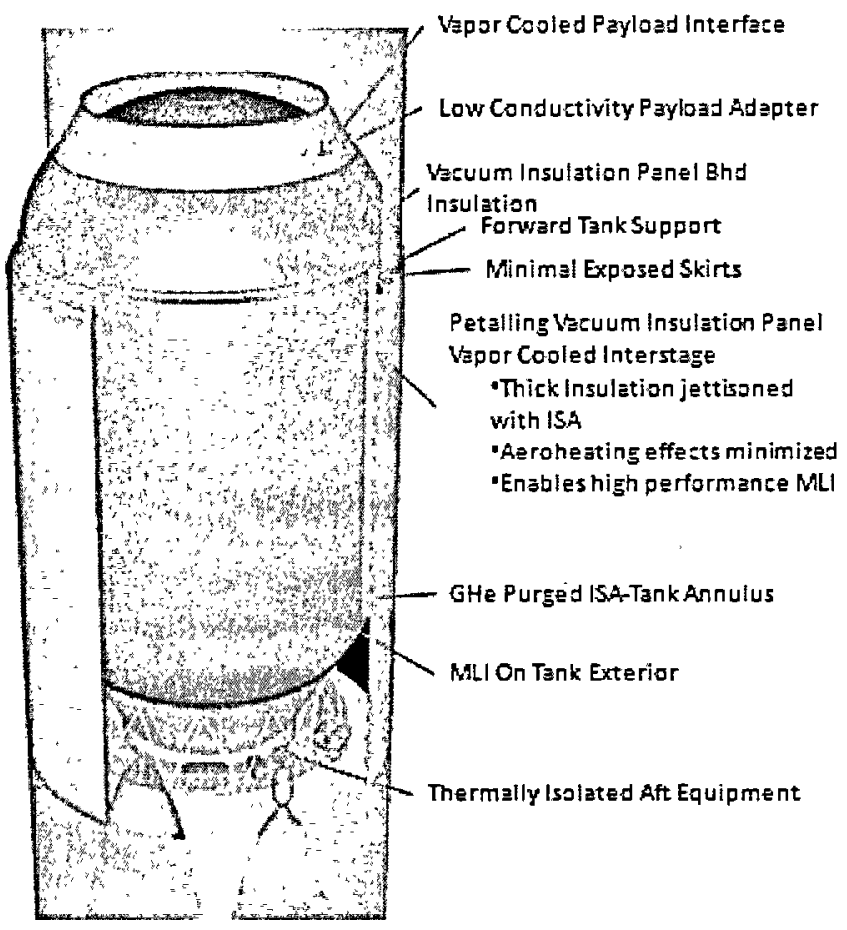

Figure 8. A conceptual SCT design.

\section{Subcooled Cryogen Tank}

The use of subcooled propellants directly impacts the design of the subcooled cryogen tank (SCT). A consequence of this subcooling is that the vapor pressure of the cryogen drops, requiring the use of a pressurant (helium for subcooling liquid hydrogen) to maintain the pressure in the tank so that the tank is not under compression by the atmosphere. The tank will have to be designed to accommodate the fill and, if required, venting of this pressurant. The design of the SCT will also affect the design of the TCS. The TCS will not only have to subcool the cryogen but also be able to extract the heat flowing into the tank while loaded with cryogen on the launch pad. If the SCT is capable of limiting the amount of heat flowing into its cryogen volume it will also reduce the demands on the TCS.

The conceptual Advanced Common Evolved Stage (ACES) being developed by United Launch Allaince (ULA) shown in Figure 8 has many innovative features that enhance the storage capability of subcooled cryogenic propellants while minimizing the required launch mass. The ACES has design features that would be beneficial for a SCT. The ACES propellant tanks are suspended from the top of a gaseous hydrogen cylinder permitting the lowest practical prelaunch internal pressures without the need for significant additional tank structure. The geometry of the upper support skirt enables it to be very short, with most of it being removed at staging. Vacuum insulation panels replace traditional foam nearly everywhere. The inter stage adapter supports all the vacuum insulation panels for the tank cylinders and because it is jettisoned at staging the mass of insulation can be amplified to suppress ground heating. The petalling separation method permits MLI to be used on the tank - sandwiched between the interstage adapters vacuum insultion panels and the tank. This cavity is purged to suppress ice or $\mathrm{LN}_{2}$ formation. Warm components are mounted well away from the cryogenic tanks on isolating structures. The payload interface is vapor cooled using gaseous hydrogen when the tank has reached a thermodynamic state where it has to be vented. The payload interface is made from low conductivity titanium/composite structures. The heat leakage into cryogenic propellant tanks of an upper stage while on the ground is typically hundreds of times what it will be once in space. The ACES design reduces this ground heating to a low multiple of the in-space heating. An ACES-like stage could also potentially be used for cryogenic in-space stages, lunar landers and fuel depots in addition to being an upper stage. This commonality would allow the TCS on the launch pad to service both upper stages, such as the EDS, and cryogenic fuel depots. 


\section{Conclusions}

Isobaric subcooling of cryogenic propellants can provide extended hold times for cryogenic propellants in space. The extended hold times would significantly benefit launch logistics of the Exploration architecture. Future long duration missions to Mars and beyond would also be enhanced by subcooled cryogenic propellants. The thermodynamic cryogen subcooler could provide an effective method for isobaric subcooling of cryogenic propellants on the launch pad with a relatively small and light system that does not require a very large electrical power supply. Most of the important components of the TCS are either at a high TRL or can be brought up to a high TRL quickly. The TCS will work well with a properly designed subcooled cryogen tank. Design features of the United Launch Alliance conceptual ACES upper stage could help reduce the demands on the TCS. If these design features are implemented on the Earth Departure Stage or stages for cryogenic propellant depots, subcooling using a TCS on the launch pad could provide many months of hold time in space for cryogenic propellants without the need to vent.

\section{Acknowledgments}

Portions of this study were made possible by funding from NASA/ Goddard Space Flight Center's Internal Research and Development program. The authors would like to thank Louis J. Salerno of NASA/ Ames Research Center for the guidance and insights provided during the composition of this paper. Shuvo Mustafi would like to thank Dr. Jungho Kim of the University of Maryland for his guidance regarding the heat exchangers for the TCS.

\section{References}

1 Tomsik, T. M., "Recent Advances and Applications in Cryogenic Propellant Densification Technology," NASA-TM-2000209941, 2000.

${ }^{2}$ Fazah, M. M., "STS Propellant Densification Feasibility Study Data Book," NASA-TM-1994-108467, 1994.

${ }^{3}$ Baik, J. H. and Raissi, A. T., "R\&D processes for increasing density of cryogenic propellants at FSEC," Cryogenics 44 pp. $451-458(2004)$.

${ }^{4}$ Salerno L. J., "Reducing Launcher Mass with Zero Boil Off or Densified Propellant Storage Systems," Unpublished in English, Published in the Proceedings of the French Cryogenic Society meeting:

Salerno, L.J., "Réduction de la masse des lanceurs par élimination de l'évaporation des ergols cryogéniques ou stockage d'ergols densifiés", 7eme Journées de Cryogénie et Supraconductivité, Paper \# AUS03S11-5, Aussois, France, May 2003

${ }^{5}$ Baik, J. H., Chang, H.M. and Notardonato, W., "Two-Stage Refrigeration for Subcooling Liquid Hydrogen and Oxygen as Densified Propellants," Cryocoolers 13 pp. $711-718$ (2004).

${ }^{6}$ Edeskuty, F. J., and Stewart, W. F, Safety in the Handling Cryogenic Fluids, Plenum Press, 1996, Chap. 10

${ }^{7}$ MoNelis, N. B, and Haberbusch, M.S., "Hot Fire Ignition Test With Densified Liquid Hydrogen Using a RL10B-2 Cryogenic $\mathrm{H}_{2} / \mathrm{O}_{2}$ Rocket Engine," NASA-TM-1997-107470, 1997.

${ }^{8}$ Notardonato, W. U., Johnson, W. L. and Jumper, K. , "Experimental Results of Integrated Refrigeration and Storage System Testing," Advances in Cryogenic Engineering: Transactions of the Cryogenic Engineering Conference, 2009 (To be Published).

9 Jums, J. M. , "Clogging of Joule-Thomson Devices in Liquid Hydrogen - Lunar Lander Descent Stage Operating Regime," Advances in Cryogenic Engineering: Transactions of the Cryogenic Engineering Conference, 2009 (To be Published).

${ }^{10}$ Muaradov, N., Smith, F., and Raissi, A. T., "Hydrogen Production by catalytic processing of renewable methane-rich gases," International Journal of Hydrogen Energy, Vol. 33, 2008, pp. 2023-2035. 